\title{
CONSTRUCTION OF GIS AND DATABASE FOR DEBRIS FLOW POTENTIAL STUDY OF CHEN-YOU-LAN RIVER WATERSHED
}

\author{
Meei-Ling Lin ${ }^{1}$ Yen-Hsu Lu ${ }^{2}$ \\ Group Leader, Office for National S\&T program for Hazard Mitigation \\ Professor, Department of Civil Engineering, National Taiwan University, \\ Taipei, Taiwan \\ Research Assistant, Office for National S\&T program for Hazard \\ Mitigation, \\ Taipei, Taiwan
}

\begin{abstract}
The problems caused by debris flows are becoming more and more serious in Taiwan. In order to perform the risk assessment for hazard mitigation, the database of debris flow rivers of Chen-You-Lan Watershed was constructed. The potential factors as well as the natural environmental data of debris flow river and basin were built into database. The client-server spatial geographic information system was built for querying, demonstration, and spatial analysis of the database. This database and GIS can be used for further analysis and classifications of potential debris flow hazard, as well as scenario simulations for hazard reduction and mitigation.
\end{abstract}

Keywords : debris flows, the potential factors, GIS, database

\section{INTRODUCTION}

Due to the vast development of economy and the limited available land in plane, usage and development of the land in mountain terrain has grown rapidly. However, the mountain terrain in Taiwan is usually very steep and fragile. Heavy rainfall carried by typhoon often causes severe hazard with slope failure.

Among all types of slope failure, debris flow often causes severe loss of human lives and properties because of its high flow velocity and large deposition area. To mitigate the hazard, risk assessment was needed and the GIS tool is used to do the analysis, demonstration, and information management of the database. In this research, the database for hazard potential study of the ChenYou-Lan river watershed was built, and the GIS provided a proper platform for spatial analysis as well as information management. For the GIS software, Arcview was used.

\section{NATURAL ENVIRONMENT DATABASE OF CHEN-YOU-LAN RIVE WATERSHED}

In order to perform analysis of debris flow hazard potential, it is necessary to construct database of the related natural environment information of the ChenYou-Lan river watershed, and to set up the structure of geographic information system. The database of the natural environment factors for the debris flow study include: the geological condition of the area, the elevation contour of the area (DEM), the river system of the area, and determination of the watershed.

The original data of the geological distribution of the area, the digital elevation model of the area, and the river system of the area were obtained from the related governmental agencies, and were integrated into the database. The watershed of the each river in the area was determined using the spatial analyzer of the GIS and the final result was modified according to the contour and sunshade maps of the local area For the Chen-You-Lan river watershed, there are a total number of debris flow watersheds. These natural environment data provided a base for further analysis and determination of the potential factors of debris flow.

\section{POTENTIAL FACTOR ANALYSIS USING GIS}

For the debris flow to occur in the field, it is necessary that certain field condition be met, which includes: enough water supply, enough amount of deposit material, and proper geomorphic condition. Based on the potential factors, the hazard potential caused by debris flow in the area could be 
determined.

According to Yu-Re Su [1] and with careful study of the probable related factors from the three conditions, it was concluded the the following potential factors might be significant for debris flow study:

1. the geomorphic factor: the angle of inclination and aspect of the side slopes in the watershed,

2. the geological factor: the distribution of geological formation of the watershed,

3. the watershed factor: the form factor of the watershed, and the hypsometric integral of the watershed are considered.

4. the stream factor: the average slope of the streambed.

\subsection{The geomorphic factor}

Peatross[2] and Williams and Guy[3] indicated that a minimum value of slope angle (approximately $40 \%$ ) seems necessary to initiate a debris avalanche. With slope angle exceeding the threshold value, the increase in slope angle does not increase the chance of failure.

Using the tool provided by the GIS, the slope angle of the study area was classified into six segment, $0^{\circ}-10^{\circ}, 10^{\circ}-15^{\circ}, 15^{\circ}-20^{\circ}, 20^{\circ}-30^{\circ}, 30^{\circ}$ $-45^{\circ}$ and above $45^{\circ}$, and area percentage of each segment were determined. Take Fun-Chou subwatershed as example, the distribution of the area by each classification is shown in Fig1.

The influence of slope aspect on the occurrence of debris avalanches is reflected by the exposure of the slope to weathering. The influences factor of slope aspect was classified as eight regions : N, NE, E, SE, S , SW , W, and NW, and the area percentage of each classification was analyzed. Take Fun-Chou subwatershed as example, the distribution of the area by each classification is shown in Fig2.

\subsection{The geological factor}

The geological structures of the well developed discontinuous planes caused the materials to collapse easily and become the source of debris. By taking the geologic map and overlapped it with the study area, the area percentage of each formation could be calculated. Take Fun-Chou subwatershed as example, the distribution of the area by each classification is shown in Fig3.

\subsection{The watershed factor}

The form factor is defined as the area of the watershed divided by the square of the stream length. Chen-Yen Yi [4] indicated that the watershed with small-form-factor has a higher probability of debris flow occurrence, because the landslide debris in the basin are easier to be moved into the main stream by the surface runoff than the watershed with large- form-factor.

The hypsometric integral is the indication of the basin's growth stage. The larger the value of the hypsometric integral indicates the more mature the basin topography is. The watershed with mature topography means the probability of the debris flow occurrence would be lower. Taking Fun-Chou subwatershed for example as shown in Fig5, the hypsometric integral can be calculated from the elevation contour and the area between each contour.

\subsection{The stream factor}

The average slope of the streambed is considered as one of the potential factor, as for the debris flow to occur, the average slope of the streambed should be within a proper range. The value is determined according to Chen-Lun Shen s[6] suggestion:

Average slope of streambed $=$

$\operatorname{Sin}^{-1}($ the upstream elevation - the downstream elevation) / the stream length)

\section{GIS FOR THE DEBRIS FLOW SUBWATERSHEDS IN THE CHEN- YOU-LAN RIVE WATERSHED}

In order to perform analysis of debris flow hazard potential, it is necessary to construct database of the related natural environment information and potential factors of the Chen-You-Lan river watershed, and to set up the structure of geographic information system. The client-server spatial geographic database is used to demonstrate the current situation of the natural environment of Chen-You-Lan river watershed, insitu photographs, and potential factors of debris flow, which could be used in the analysis of debris hazard. The Access is used as the database system for the server, which contains the attributes data. The ArcView software is used as the spatial data demonstration system for the client, and the ODBC system is used to link the database and query system. For the query system, Visual Basic was used for demonstration of the attributes, which provided a friendly interface for the user. All of the authorized user can access the database easily through intranet. Only browsing and querying of the data instead of editing was provided to the user, the database manager has absolute authority over the database. The relationships among ArcView, Access the database, Visual Basic and ODBC are as shown in Fig6. All the potential factors of debris flow in the Chen-You-Lan river watershed are generated and built into database for the GIS system. For the ChenYou-Lan river watershed, there are a total number of 51 debris flow rivers, distribution of the subwatersheds and its potential factors are as shown in Fig7. 


\section{CONCLUSIONS}

By using the tool provided in the GIS system, the database of the potential factors needed for the hazard potential study of the debris flow watershed could be easily analyzed and obtained. The natural environment data, the developed potential factors data, as well as the in-situ photographs and other information were all integrated well and could be demonstrated as spatial database in GIS. The database constructed under GIS proved to be a powerful and helpful tool for analysis of hazard potential, data management, query and demonstration of the database for debris flow hazard mitigation.

\section{References}

[1] Su-Yu-Ren , 1995. Application of GIS on risk assessment of the debris flows in Hualien area. Masters thesis, National Taiwan University , 55-61 pp.

[2] Peatross, J.L., 1986. A morphometric study of slope stability controls in Virginia. Masters thesis, Univ. of Virginia, $150 \mathrm{pp}$

[3] Williams, G.P. and Guy, H.P., 1971. Debris avalanches-A geomorphic hazard .In: D.R. Coates (Editor), Environmental Geomorphology. SUNY, Binghamton, Binghamton, N.Y., 25-27 pp.

[4] Chen-Yen Yi , 1993. The properties of the debris flow in Taiwan, Conference of the applied geotechnical engineering properties $(\mathrm{V}), 70$ $90 \mathrm{pp}$.

[5] Auer, K. and Shakoor, A., 1989. Geotechnical characterization of drainage basin stability with respect to debris avalanches in center Virginia. Bull. Assoc. Eng. Geol., 26: 387-395pp.

[6] Chen-Lun Shen , 1991. The study of the warning system in debris flow. Laboratory report, N.C.K.U.
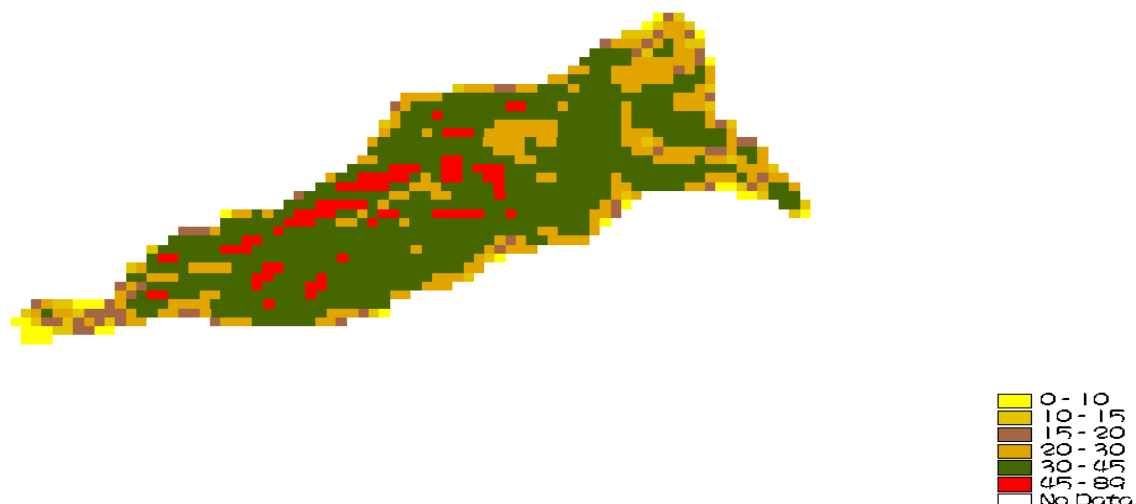

Fig1 The distribution of the area by each classification of the slope inclination

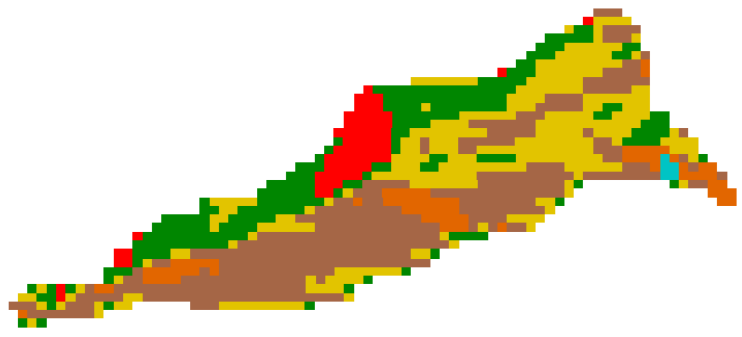

Fig2 The distribution of the area by each classification of the slope orie 


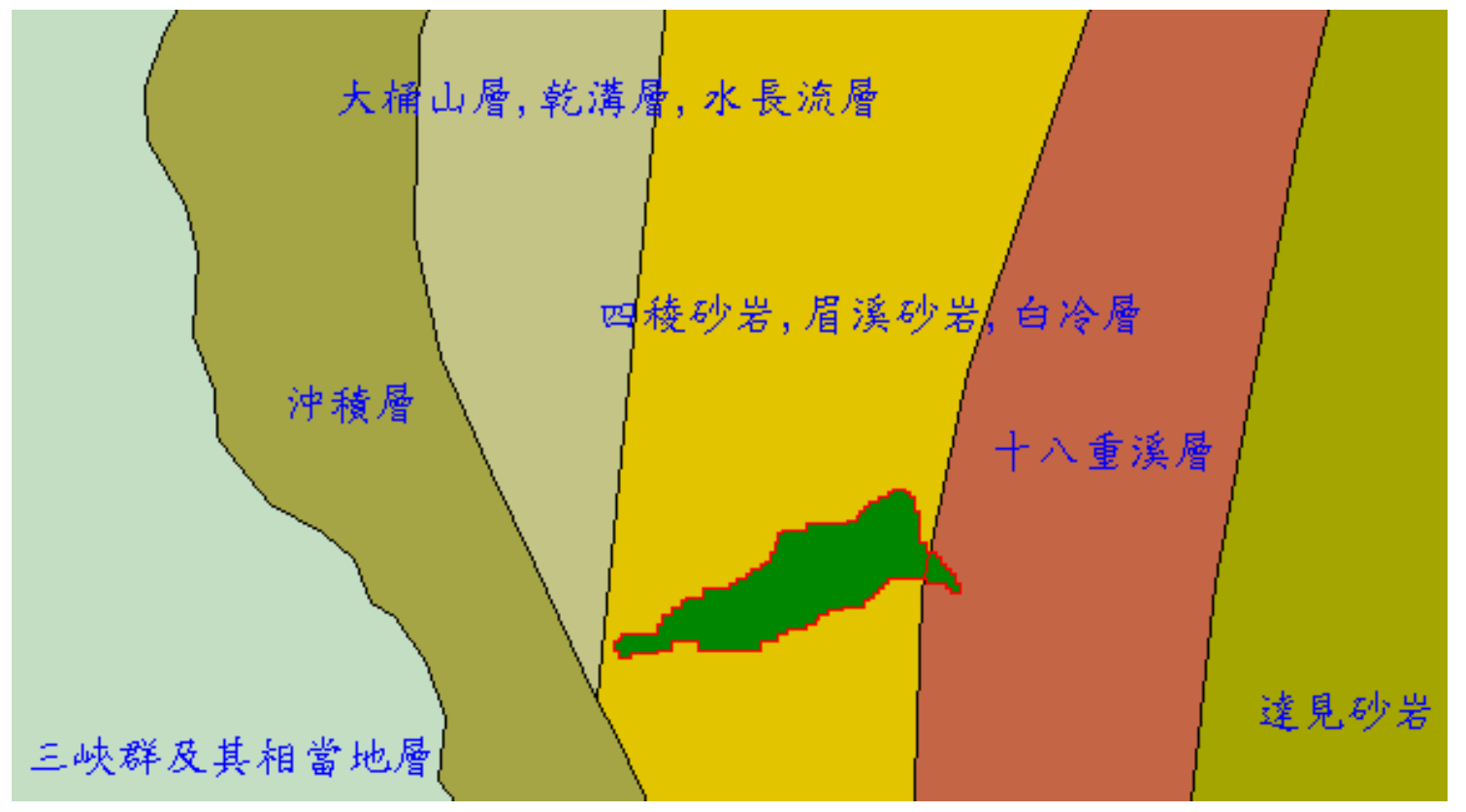

Fig3 The distribution of the geologic map of the Fun-Chou basin

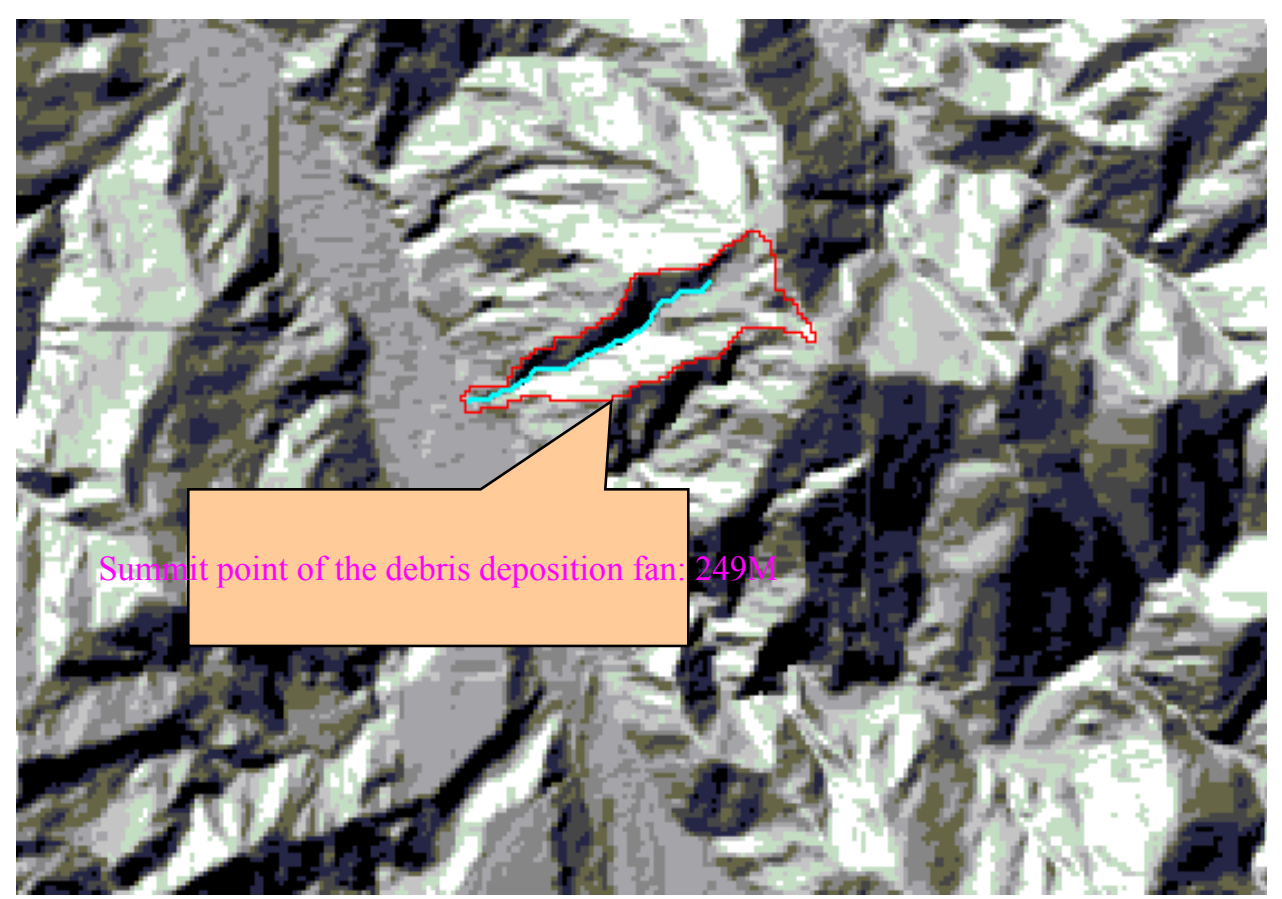

Fig4 The locating result of the summit point of the debris deposition fan 
Fig5 The contour and area slices in Fun-Chou basin

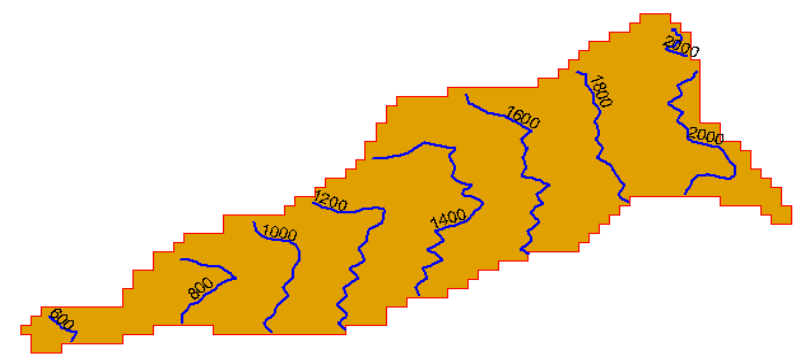

$800 \quad 0 \quad 8001600$ Meters

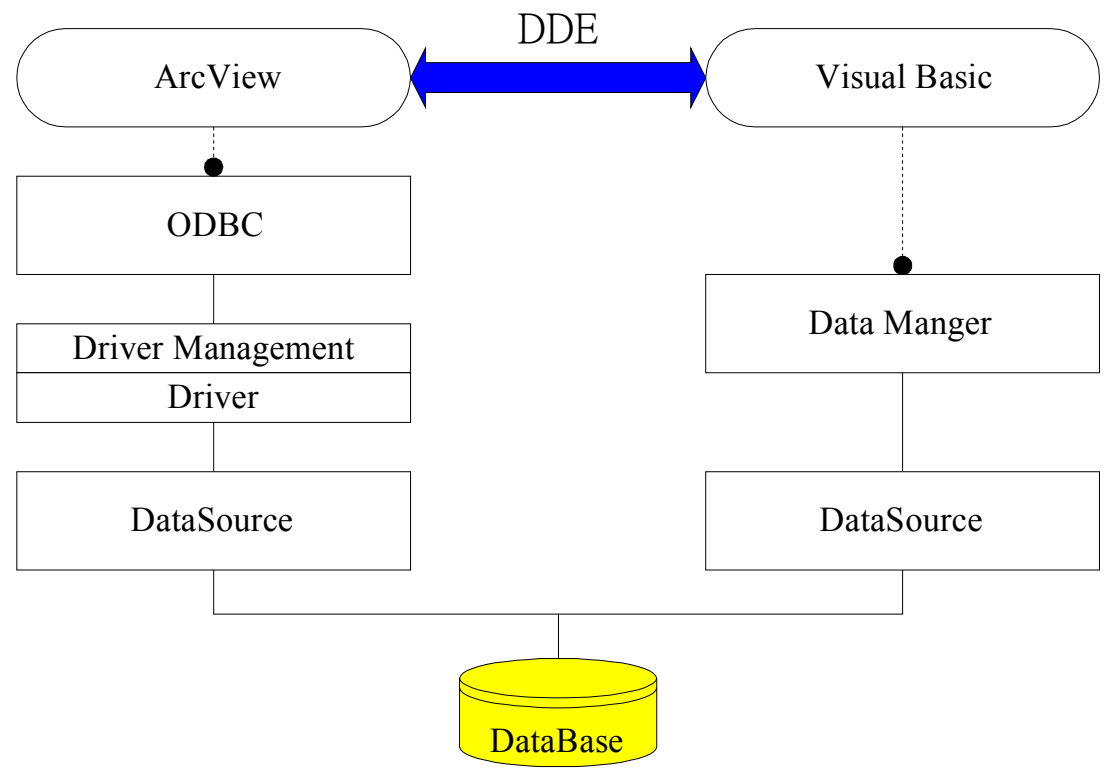

Fig 6 The relationships among ArcView, Access the database, Visual Basic and ODBC 


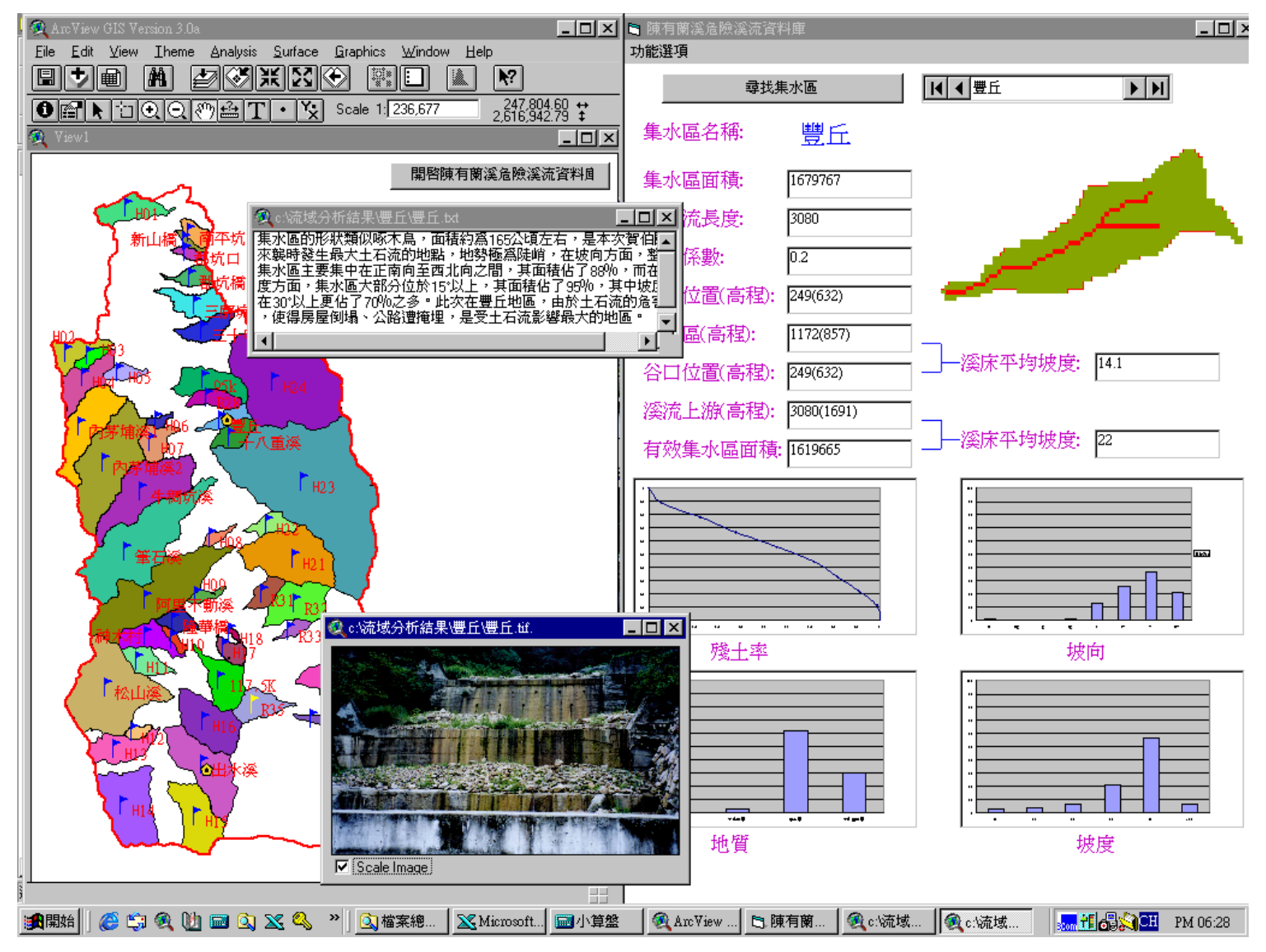

Fig 7 The Chen-You-Lan River spatial geographic database 